\title{
LA CADENA Y EL OCÉANO: ACERCA DE DOS METÁFORAS
}

Francisco J. Furnández*

"Comment échapper à cette instance [la de lo metafórico] si l'on veut se limiter à situer le discours épistémologique dans la dispersion des discours en quoi consiste aujourd'hui la philosophie, dès lors qu'aucun discours unitaire, aucune théorie globale, aucune doctrine fondatrice n'autorise à résorber dans l'unité d'un savoir cette dispersion, en la réduisant à l'apparence des opinions?".1 Lo que me propongo no es tanto comentar esta cita de Michel Fichant (la cual apareció en un contexto que exigiria desembocar en autores - Althusser, Bachelard- y conceptos un tanto alejados del marco de este Congreso) cuanto intentar hacer ver algo sobre lo que, por otra parte, el propio Fichant o Yvon Belaval, entre otros, han Ilamado la atención; a saber: cómo en tiempos en los que la unidad del saber adquirió el rango de tesis consciente de la propia marcha especulativa, la instancia de lo metafórico era no obstante paralela al propio despliegue teórico.

La presencia de una metáfora muestra en general el rastro de una sustitución. Cuando la metáfora comparece en un texto filosófico, se suele pensar que ello obedece o a un procedimiento retórico o a una insuficiencia conceptual. Puede, incluso, darse el caso de que su presencia tenga por objetivo camuftar tal eventual insuficiencia teórica mediante el recurso y la instancia de lo metafórico. Indicio para esto último es normalmente la percepción de la violencia de la metáfora empleada, pues que no se ve bien qué está siendo sustituido exactamente, pues que no se ve bien a qué obedece tal recurso. En cualquiera de estos casos, sin embargo, la metáfora no deja de pertenecer ni por un momento a un registro que se mueve entre lo subsidiario y la escasez, es decir, un registro francamente subordinado, un registro de artificio (en el doble sentido de banal y engahioso). Todo ello es màs o menos ajustado, pero a veces ocurre que hay metáforas que se solidarizan tanto con el sistema en el cual aparecen que escapan al cabo al marco de posibilidades recién descrito. Es decir, metáforas que pierden su carácter de recurso o excepción en favor de su conversión en marco mismo del sistema, esto es, metáforas que se convienten en tesis isomorfas con la constitución del propio discurso teórico. La de la cadena en Descartes y la del océano en Leibniz serian de estas últimas. La manera que tendriamos a la hora de legitimar este presencia se resume en esta propuesta: la de considerar los conceptos en tanto que procedimientos de identificación y las metáforas en tanto que mecanismos de desplazamiento. Para ilustrar este peculiar funcionamiento, asi como las formas correctas de aprovecharse de él, recordaré la metáfora de la cadena, empleada por Descartes frecuentemente. ${ }^{2}$ Tras ello, la contrapondré a la del océano, emplenda a su vez por Leibniz con cierta asiduidad. Lo que pretendo es exponer cómo estos mecanismos de desplazamiento funcionan de hecho. Si se consigue, se verán tres cosas. La primera, cómo ciertas metáforas se relacionan con ciertos conceptos (cadena y océano en Descartes y Leibniz respectivamente) y su común destino en tanto que ancladas a la tesis de la unidad de la ciencia. La segunda, cómo una metáfora se inodifica en función de una identificación conceptual

\footnotetext{
"Becario de F.P.I. del Gobierno Vasco-Eusko Jauriaritza (1995-1996) en el Institut d' Ilistoire et Philosopluie des Sciences et des Techniques (Paris I, Pantheon-Sorbone).

1 M. Fichant, "L'épistémologie en France", en Hisfoire de la Philosophie. Llées, Doctrines (bajo la dirección de F. Clistelet), Paris, Hachette, 1973, t. VIIt, p. 176.

2 Cfr., M. Serres, La Tradiction (1 lermes III), Paris, Les Éditions de Minuit, 1974, pp. 107-110.
} 
(el caso cartesiano ${ }^{3}$ ). La tercera, cómo permanece una metáfora en función de un desplazamiento teórico (el caso de Leibniz ${ }^{4}$ ). Sólo los casos segundo y tercero involucran cierto peligro, pues que tienen que estar más o menos claras tanto las razones de la identificación conceptual como las razones de la permanencia metaförica. [...]

Conseguido esto, lo que estos preliminares exigirian es examinar después la diferente disposición conceptual de las metáforas empleadas por Descartes y Leibniz. Las razones, por ejemplo, para que la unidad de la ciencia se lea mejor en Descartes mediante la metáfora de la cadena o del árbol que mediante la leibniziana del océano. Se descubriria entonces que nociones subalternas, como la de jerarquía entre disciplinas o la de la rigidez del todo del saber, hallan metáforas ( $y$ hasta alegorias) que las jlustren en un caso (Descartes), pero no en otro (Leibniz). Pero lo que en cualquier caso me interesaba estaba allende estos desarrollos. Me interesaba más aliarlos que distinguirlos. De ahi que lo que de todo esto quisiera que se desprendiera sea más bien una suerte de demostración: la de que la presencia de la instancia cle lo metafórico no es patrimonio de un discurso debilitado, sino constitutivo o, mejor, paralelo a la propia marcha teórica, ya sea para contribuir a la extracción de nuevos conceptos (lo que se podría llamar la virtud sintética de las metáforas), ya sea para precisarlos (su virtud analítica), ya sea para combatirlos (su virtud dialéctica). Pero, en fin, cabe sospechar que la unidad del saber a la que, en última instancia, tanto la cadena como el océano aspiraban en aquel tiempo fuera algo más que una invitación: cabe sospechar, asimismo, que la actual c institucional dispersión del saber se deriva tanto de la ausencia de un concepto que la combata como de una metáfora que ilustre ese combate, pues que ni siquiera hay ahora metáfora para éste.

3 En el que se observa la modificación de la metâfora de la 'cadena', pues Descartes apuesta en algún moinento por la clásica del 'úrbol'. A hora bien, la unidad orgánica que el árbol ilustra (cfr. Carti-prefacio a Picor de 1647) es paralela a la unidad concatenada de las diferentes ciencias (catena scientiarum).

4 Desplazamiento consistente en efectuar consideraciones teológicas (Océano identificado a Dios: «Les perfections de Dieu sont celles de nos âmes, mais il les possède sans bornes; il est un océan, dont nous n'avons reçu que dis goutles", en Essais de Théodicée sur la Bonté de Dieu, la Liberté de I'Homme er l'Origine du Mal, td. de J. Brunschwig, Paris, Flammarion, 1969, Prefacio, p. 27, autorizando, claro está, tal identificación, o ya para desacreditar paradójicamente tal desplazamiento, como, por ejermplo, en sus Considerations sur la docirine d'um esprit universel unique de 1702, siguiendo por olsa parte a Pierre Bayle, articulo 'Spinozn' de su Dicsionaire historique et critique) alll donde sólo estaban presentes consideraciones epistemológicas (Océano identificado a la unidad de la ciencia, cfr, entre muchos otros lugares, Leibniz, Nowreanx essais sur l'entendemen humaine, Libro IV, cap. XXI). 